\title{
Micro Enterprise (MEs) Upgrading in Indonesia: Why MEs are not Growing?
}

\author{
Atika Rukminastiti Masrifah ${ }^{1}$, Setiawan Bin Lahuri ${ }^{2}$, Muhammad Ridho Zarkasyi ${ }^{3}$, \\ and Syamsul Hadi Untung 4 \\ \{atikamasrifah@unida.gontor.ac.id ${ }^{1}$, binlahuri@unida.gontor.ac.id ${ }^{2}$ \} \\ ${ }^{1}$ Department of Islamic Economics, University of Darussalam Gontor Indonesia \\ ${ }^{2}$ Department of Sharia Economic Law, University of Darussalam Gontor Indonesia \\ ${ }^{3}$ Department of Management, University of Darussalam Gontor Indonesia \\ ${ }^{4}$ Department of Aqidah and Islamic Thought, University of Darussalam Gontor Indonesia
}

\begin{abstract}
Indonesia had a vast number of micro, and small enterprises and only a few larger enterprises, more than 90 per cent of firms were micro-sized enterprises (MEs). Empirical evidence suggested that most of them stagnated and never graduated into the segment of the medium even small-size enterprises, only a small minority of them graduated to the next size category. This research referred to this group as upgrades. It raised the question as to which factors determined the upgrading of MEs into higher scale. The target population of this study was MEs which graduated to small enterprise, operating in different lines of business. The sample size of this study was 209 enterprises. Responses of the subjects were collected through questionnaires. Structural Equation Model (SEM) was used for analysis. As a result, the main factors determined the upgrading of MEs was shaped by internal (i.e. financial literacy, operational training, accessibility to a financial institution) as well as external (i.e. policy, social environment, challenge) factors. SEM results showed that financial literacy and operational training were the most critical determinant to upgrade the scale level of MEs. Meanwhile, lack of accessibility to the financial institution could not stop them from surviving, since they financed by their capital. External factors also contributed significantly to the upgrading of MEs. Eventually, the research provided policy recommendations not only specific to develop microenterprise, but should further upgrade the size of micro size enterprises in operation, management and policy.
\end{abstract}

Keywords: Enterprises Upgrading, Micro Enterprises, Operation Management and Policy. 


\section{$1 \quad$ Introduction}

Indonesia has an enormous number of micro and small businesses, and only a few more prominent businesses, with more than 90 per cent being micro-sized businesses (MEs). Various data reveal that MEs has an enormous contribution to company numbers, GDP, labour numbers and exports.

Table 1. Statistics of Micro, Small and Medium Enterprises in 2017.

\begin{tabular}{lcccccc}
\hline & \multicolumn{2}{c}{ Number } & GDP & \multicolumn{2}{c}{ Labor } & Export \\
\hline Micro & 62.106 .900 & $98.70 \%$ & $36.82 \%$ & 107.232 .992 & $89.17 \%$ & $1.26 \%$ \\
Small & 757.090 & $1.20 \%$ & $9.61 \%$ & 5.704 .321 & $4.74 \%$ & $2.48 \%$ \\
Medium & 58.627 & $0.09 \%$ & $13.57 \%$ & 3.736 .103 & $3.11 \%$ & $10.44 \%$ \\
Large & 5.460 & $0.01 \%$ & $40.00 \%$ & 3.586 .769 & $2.98 \%$ & $85.83 \%$ \\
MSMEs & 62.922 .617 & $99.99 \%$ & $60.00 \%$ & 116.673 .416 & $97.02 \%$ & $14.17 \%$ \\
\hline
\end{tabular}

Source: Ministry of Cooperation and SMEs processed from Statistics Indonesia

MEs are very different companies with their distinctive characteristics. In traditional and informal markets, MEs have large numbers of units. MEs are usually managed by a single employee and are therefore resistant to fluctuations in the business cycle. Stagnation of micro companies and the productivity gap is not only a problem for individual companies, but also has consequences on economic competitiveness and social integration.

Many empirical studies show that most MEs are not improving their businesses to the next level of productivity, assets and employment in developing countries. Most of them stagnant [1] and will only graduate to the next size class in the medium-sized segment, even smaller companies. Instead, most companies stagnate, close and leave the market. While the chances of MEs being upgraded to a higher size or productive segment are meagre, there are no exceptions. A group of MSEs exists which have succeeded in upgrading into the medium or large segment. These groups were called upgraders in this study. It asked about the factors which led to the higher-level reclassification of MEs.

This paper is intended to study the upgrading of Micro Enterprises (MEs) in Indonesia, to analyze why MEs are not growing to graduate into Small Enterprises (SEs). In this paper, ME's upgrading template for ME to graduate from ME to SE should be designed. MEs, which graduates into a small business operating in various business lines, were the target population of this study. Two hundred nine companies were sampled in this study. The subjects ' answers have been obtained via questionnaires. For analytical purposes, Structural Equation Model (SEM) was used. 


\section{$2 \quad$ Literature Review}

Micro Enterprises, which are operated on a micro scale, have relatively few or no permanent employees and as ME is not formally registered they do not have access to formal financial services. In this section, we will discuss different definitions of MSMEs. In general, sales volumes, capital sizes and asset sizes may be used to define MSMEs. The differences in the market structure, policies and legal systems in each country can lead to different classifications of MSMEs [2].

MSMEs are defined differently in Indonesia by several institutions and by law. In Statistics Indonesia defines MSMEs by their employee numbers, for example. Companies that hire less than five employees are classified as MEs including family employees, while SEs have around five employees to 19 employees.

These categories are only provided by total employees without taking into account their capital and total annual sales. The MSMEs Act No.28 Year 2008 further defines the ME-based on annual sales (under Rp 300 million), total assets (under 50 million excluding real estate), and non-subsidiary large businesses. Furthermore, SEs could be classified based on annual sales and total assets (Rp300 million to Rp2,5 billion).

Moreover, this section also deals with a brief review of the business cycle framework. The cyclical business model explains that a company must undergo a specific phase in its evolution process. Each model has various features and numbers of stages. The five stages of growth as an organizational development process [3]. The growth phase model was creativity, management, delegation, coordination and cooperation. At the end of the period, each phase encountered crisis to define the next phase. To address this problem, the company had to use new business techniques to pull an active manager, who had good knowledge and expertise. A further investigation into the cycle of business life used Greiner's Theory of Development and Revolution as the fundamental concept.

Another critical investigation into the business cycle was identifying 10 life stages as follows: (i) courtship (first business creation); (ii) infancy (starting sales to crucial clients, capital raising and/or recruitment of crucial talent); (iii) go - go (fast sales growth and sometimes chaos); (iv) the adolescence (the success of a well-performing company, sales slowing, or an infrastructural collapse of an infrastructure); (v) the prime (the optimum lifecycle position); (vi) the stable (still profitable but beginning to loses its vitality); (vii) aristocracy (consolidated success but lower growth and market share expectations); (viii) early bureaucracy (threats, problems, organization paranoia), (ix) bureaucracy (internally disassociated and cumbersome) and (x) death (failure and closure) [4].

Churchill and Lewis [5] further developed a "classic" model according to Greiner's and Adizes ' models. A company could have 5 phases of growth: existence, survival, success, departure and maturity of resources . At the time of the company's existence, its processes and work were still established without any formal structure. Secondly, the stage of survival forced the company to grow through additional capital. The company has started earning profits and capital at the third stage of its success so that it can invest in the future business by building a team. The company has begun creating fur- 
ther growth, expansion and new opportunities on the start-up stage. Finally, the company became a more prominent business at the resource maturity stage with its focus on quality control, financial control and market niche creation.

Scott and Bruce [6], through five phases of growth with their distinctive characteristics, depicted a model of small business growth. These phases were classified as starting, surviving, growing, expanding and maturing. The model helped managers plan and solve the problem of small businesses grow.

Initially, Humphrey and Schmitz [7] introduced the concept of upgrading in the global value chain. They focused mainly on four different types of upgrades: product upgrade, process improvement, functional upgrade and intersectional upgrade. Meanwhile, Reeg defined improvement as the growth of innovative MSMEs [8]. He identified five pathways through which product, process, marketing, functional and industry innovations can be implemented. The determinants of upgrading were also discussed in this section.

There are always companies which started, while others expanded, contracted or even closed. Also, the majority of MSMEs were stagnant in other empirical studies. Few small and micro companies could move to medium-sized enterprises via productivity, assets, and workers, known as upgrades. The revaluation defines upgrading as company growth triggered by innovation at a company level.

Conceptually, upgrading of enterprises has two constituent elements-quantitative and qualitative: firstly, improving enterprises means becoming an explosion in income, productivity and employment, from being a company with stagnation or a decrease in income and to a growing business that continually increases its revenue, productivity and the number of paid employees (company growth). On the other hand, improving enterprises also means improving the quality of products, processes and ways of manufacturing. These qualitative changes enable the company to collect innovation rents, increase the added value and become competitive over the long term.

Some studies focus on MSMEs upgrading (Reeg, Loewe, et al., and Hampel-Milagrosa) are conducted. The union model is used by Reeg [9] to identify success factors and constraints in the upgrade of MSEs in India. To this end, a qualitative study used description and analysis of case-by-case successes of medium and large companies across three sectors in India-ICT, the textiles and clothing sector and the leather and footwear sector. The study compares successful cases (upgrades) with current microentrepreneurs (non-upgraders) within the same field, learned from individual experiences. He suggests that the business upgrade model should include five layers (entrepreneur features, corporate features, social networking, business networks, and business environment).

Loewe et al. [10], taking the case of Egypt, used a similar method to identify the success factors and limitations of upgrading the MSEs. Those factors can be grouped into 4 layers, using the onion model for corporate upgrading: (i) the characteristics of the enterprises, (ii) the entrepreneur's nature, (gender, human capital, social capital, family background and the personal properties of the MSME owner), (iii) the integration of MSMEs into value chain operational clusters or enterprise networks such as 
business associations), (iv) the interconnected environment for business (macroeconomic and political stability, rules, regulations, taxation, trade, corruption, access to finance, business development and infrastructures).

Hampel-Milagrosa [11] uses and adjusts their research to develop MSE improvements in the Philippines using a similar onion model developed by Reeg [8] and Loewe et al. [10]. Four layers should be included in the onion model. The first level concentrates on the contractor (education, training, motivation, etc.) as the only force for upgrading businesses. The core of the Onion model is this entrepreneurial element. The second layer points out the characteristics of companies and employees (company age, location and industry) as incentives for modernisation. The $3^{\text {rd }}$ level shows the interactions between businesses and companies as driving forces for corporate growth, with personal and professional networks. The fourth and ultimate layer refers to the quality of the business environment and how the company upgrades to this layer.

\section{$3 \quad$ Research Methodology}

This study includes qualitative techniques, which require qualitative data, in particular, Structural Equation Modeling (SEM). To progressively improve the SEs graduation method, the determinants for micro-entities (MEs) are analyzed. A field survey provides the primary data necessary for this study, in which 209 samples from customers of Islamic and conventional financial institutions are selected, including those receiving loans from conventional financial institutions and financings from Islamic financial institutions and those receiving no loans or financing.

In the first stage, Karl Jöreskog [12] developed structural Equation Modeling (SEM), together with the model Keesling [13] and Wiley [12] , which he named JKV, the socalled Linear Structural Relation (LISREL) model.

In economics (which uses measured/observed variables), SEM is developed from the simultaneous equation using a variable that is not directly measured (also termed latent variables). Jöreskog and Sörbom, which are called LISREL (interactive and easy to use), are the development of the supporting computer software.

Two key components are SEM: 1) Structural Model, that describes by theory measured or estimated indirectly, structural relations among the latent variables, unobserved variables, or constructs or factors; 2) Measurement Model, which provides a description, using the concept 'Confirmatory Factor Analysis' or 'Exploratory Factor Analysis', of the indicator variables or measured variables reflecting or measuring or estimating their respectively latent variables. 
SEM model of this study comprises of three latent exogenous variables, namely Challenge $\left(\xi_{1}\right)$, Policy $\left(\xi_{2}\right)$ and Environment $\left(\xi_{3}\right)$, as well as four latent endogenous variables, namely Financial Literacy $\left(\eta_{1}\right)$, Accessibility to Financial Institution $\left(\eta_{2}\right)$, Operational Training $\left(\eta_{3}\right)$, and Upgrading of MEs $\left(\eta_{4}\right)$. The corresponding structural equations are exactly similar to equations $1-4$.

$$
\begin{gathered}
\eta_{1}=\gamma_{11} \xi_{1}+\gamma_{12} \xi_{2}+\gamma_{13} \xi_{3} \\
\eta_{2}=\gamma_{21} \xi_{1}+\gamma_{22} \xi_{2}+\gamma_{23} \xi_{3} \\
\eta_{3}=\beta_{31} \eta_{1}+\beta_{32} \eta_{2} \\
\eta_{4}=\beta_{41} \eta_{1}+\beta_{42} \eta_{2}+\beta_{43} \eta_{3}
\end{gathered}
$$

This study can thus illustrate the entire SEM model like Figure 1. Challenge, Policy, Environment, Financial Literacy, Accessibility to Financial Institution and Operational Training are the causes of MEs upgrading in Indonesia.

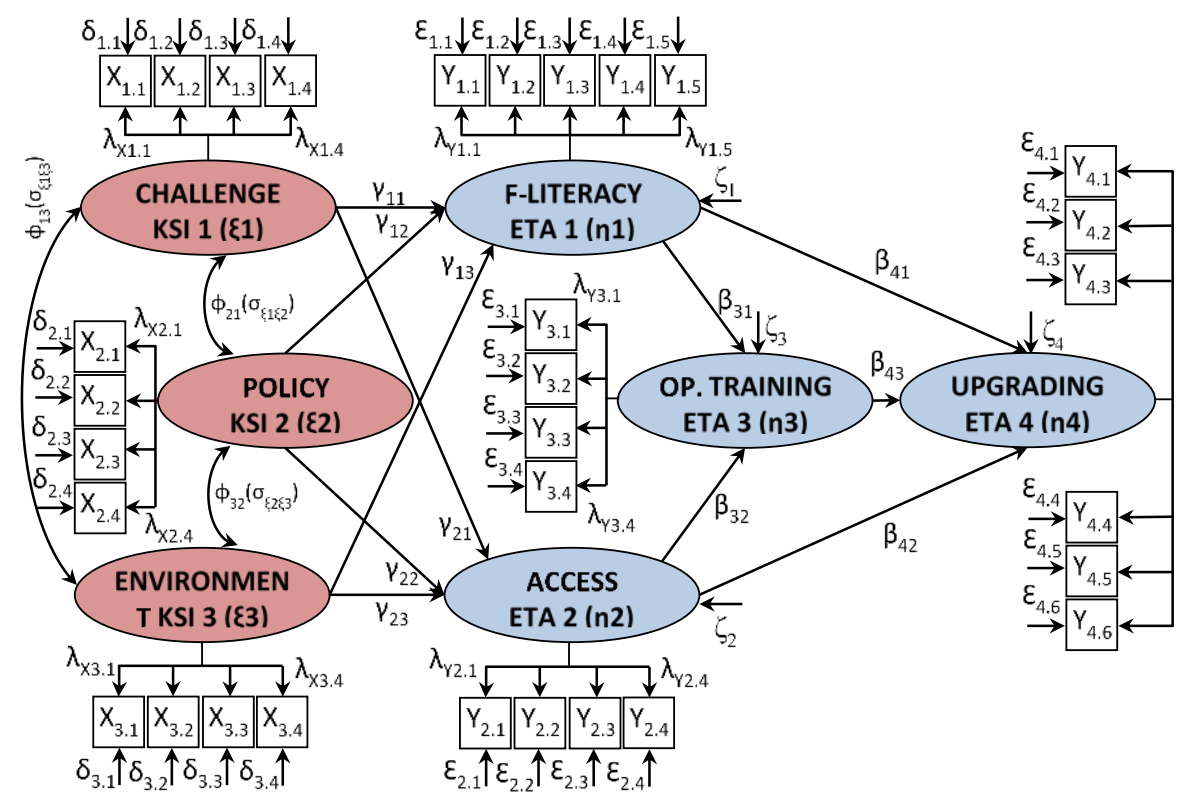

Fig. 1. SEM Model of Micro Enterprise (MEs) Upgrading in Indonesia 


\section{$4 \quad$ Result and Analysis}

SEM results are the final process for several SEM procedures, begun by specifying, identifying, estimating, testing and final results. The author can obtain the full results of all SEM procedures.

The results of seven measurement models will be discussed, consisting of three latent exogenous variables (Challenge, Policy and Environment) and four latent endogenous variables (Financial Literacy, Operational Training, Accessibility to Financial Institution).

1. All measured variables $\left(\mathrm{X}_{1.1}-\mathrm{X}_{1.4}\right)$ significantly explain CHALLENGE. Networking $\left(\mathrm{X}_{1.2}\right)$ and Funding $\left(\mathrm{X}_{1.1}\right)$ have the highest loading factors, followed by Competition $\left(\mathrm{X}_{1.3}\right)$ and $\mathrm{ICT}\left(\mathrm{X}_{1.4}\right)$.

$\chi^{2}=0.09 ; \mathrm{df}=1 ; \mathrm{p}=0.76 ;$ RMSEA $=0.00 ;$ AGFI = 0.99; Conclusion: CLOSE FIT

2. All measured variables $\left(\mathrm{X}_{2.1}-\mathrm{X}_{2.4}\right)$ significantly explain POLICY. Bureaucracy $\left(\mathrm{X}_{2.3}\right)$ and Export Policy $\left(\mathrm{X}_{2.4}\right)$ have the highest loading factors, followed by Symmetric Information $\left(\mathrm{X}_{2.3}\right)$ and Foreign Market $\left(\mathrm{X}_{2.4}\right)$.

$\chi^{2}=1.15 ; \mathrm{df}=2 ; \mathrm{p}=0.56 ; \mathrm{RMSEA}=0.00 ; \mathrm{AGFI}=0.99 ;$ Conclusion: CLOSE FIT

3. All measured variables $\left(\mathrm{X}_{3.1}-\mathrm{X}_{3.4}\right)$ significantly explain SOCIAL ENVIRONMENT. Management Waste $\left(\mathrm{X}_{3.1}\right)$ and Lack of Knowledge $\left(\mathrm{X}_{3.3}\right)$ have the highest loading factors, followed by Eco-Friendly $\left(\mathrm{X}_{3.2}\right)$ and Infrastructure $\left(\mathrm{X}_{1.4}\right)$.

$\chi^{2}=2.15 ; \mathrm{df}=2 ; \mathrm{p}=0.34 ; \mathrm{RMSEA}=0.02 ; \mathrm{AGFI}=0.97$; Conclusion: CLOSE FIT

4. All measured variables $\left(\mathrm{Y}_{1.1}-\mathrm{Y}_{1.5}\right)$ significantly explain FINANCIAL LITERACY. Budgeting $\left(\mathrm{Y}_{1.2}\right)$ and Accounting Information $\left(\mathrm{Y}_{1.3}\right)$ have the highest loading factors, followed by Financial Report $\left(\mathrm{Y}_{1.4}\right)$ and Supervision $\left(\mathrm{Y}_{1.5}\right)$ as well as Journal Entry $\left(\mathrm{Y}_{1.1}\right)$.

$\chi^{2}=8.47 ; \mathrm{df}=5 ; \mathrm{p}=0.13 ; \mathrm{RMSEA}=0.06 ;$ AGFI $=0.95$; Conclusion: CLOSE FIT

5. All measured variables $\left(\mathrm{Y}_{2.1}-\mathrm{Y}_{2.4}\right)$ significantly explain ACCESSIBILITY TO FINANCIAL INSTITUTION. Source from Banking $\left(\mathrm{Y}_{2.1}\right)$ and Micro Financial Institution $\left(\mathrm{Y}_{2.4}\right)$ have the highest loading factors, followed by Cooperation $\left(\mathrm{Y}_{2.2}\right)$ and Family Loan $\left(\mathrm{Y}_{2.3}\right)$

$\chi^{2}=0.29 ; \mathrm{df}=1 ; \mathrm{p}=0.59 ; \mathrm{RMSEA}=0.00 ; \mathrm{AGFI}=0.99 ;$ Conclusion: CLOSE FIT

6. All measured variables $\left(\mathrm{Y}_{3.1}-\mathrm{Y}_{3.4}\right)$ significantly explain OPERATIONAL TRAINING. Motivation Training $\left(\mathrm{Y}_{3.2}\right)$ and Accounting Training $\left(\mathrm{Y}_{3.1}\right)$ have the highest loading factors, followed by Business Plan Training $\left(\mathrm{Y}_{3.3}\right)$ and Financial Training $\left(\mathrm{Y}_{3.4}\right)$

$\chi^{2}=3.05 ; \mathrm{df}=2 ; \mathrm{p}=0.22 ; \mathrm{RMSEA}=0.05 ; \mathrm{AGFI}=0.96$; Conclusion: CLOSE FIT

7. All measured variables $\left(\mathrm{Y}_{4.1}-\mathrm{Y}_{4.6}\right)$ significantly explain UPGRADING. Production Cost $\left(\mathrm{Y}_{4.2}\right)$ and Number of Employee $\left(\mathrm{Y}_{4.5}\right)$ have the highest loading factors, followed by Improvement in Business Conditions $\left(\mathrm{Y}_{4.3}\right)$, Net Income $\left(\mathrm{Y}_{4.4}\right)$ and Product Demand $\left(\mathrm{Y}_{4.1}\right)$ as well as Turnover $\left(\mathrm{Y}_{4.6}\right)$ $\chi^{2}=14.56 ; \mathrm{df}=8 ; \mathrm{p}=0.07$; RMSEA $=0.06 ;$ AGFI $=0.94$; Conclusion: CLOSE FIT 


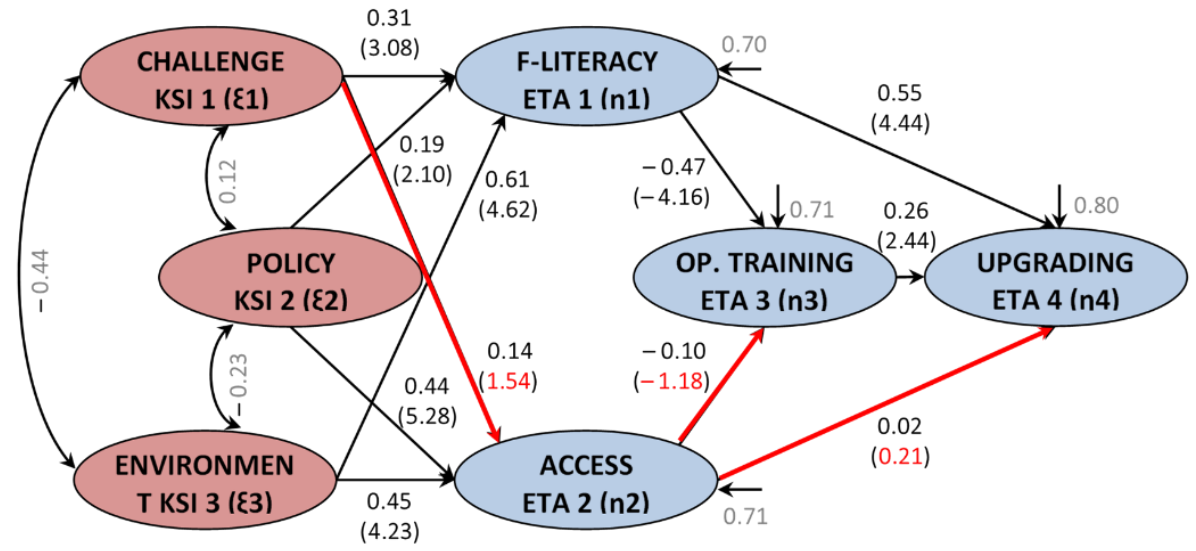

Fig. 2. Structural Model of MEs Upgrading in Indonesia

The MEs upgradings' Structural Model meets three main conditions, namely $\chi^{2 / \mathrm{df}}$ $\leq 3.0$ (1122.37/417), $\mathrm{P}<0.050(0.00)$ and RMSEA $\leq 0.08(0.00)$. All fitness measures (GoF) are fit, so we can conclude that the MEs upgradings' structural model is a good model with a close fit. Factors affecting MEs upgrading include Latent variables FINANCIAL LITERACY and OPERATIONAL TRAINING significantly affect UPGRADING directly, as well as Latent variables CHALLENGE, POLICY and SOCIAL ENVIRONMENT significantly affect UPGRADING indirectly.

Directly, financial literacy $(0.55)$ and operational training $(0.26)$ are the most critical factors determining ME graduation, as well as external factors, such as challenge, policy and environment (indirectly). The most critical variables that determine the upgrade of MEs are information for budgeting and accounting, as well as their training, like networking, export policy and waste management also have a significant impact on the upgrade of MEs.

As a result, the main factors determine the upgrading of MEs is shaped by internal (i.e. financial literacy, business training, accessibility to the financial institution) as well as external (i.e. global market, social environment, challenge) factors. The SEM results show that financial literacy and business education are the most crucial factor in improving the size of MEs. In the meantime, lack of access to financial institutions could not prevent them from surviving, as they were financed by their capital. External factors also make a significant contribution to MEs upgrades.

Successful MEs must have functional financial literacy and a good understanding and ability to win the market, especially in its business processes using information technology optimally. Also, it is essential that ME succeeds in a business environment with excellent infrastructure and stable macroeconomic conditions, as well as continued family support and their family environment. Moreover, other factors must not be ignored as they are (but not adequate) necessary for ME to work and succeed, particularly the visionary and entrepreneurial experience of the owner, as well as of skilled human resources. 


\section{Conclusion and Recommendation}

The primary considerations for why companies differ in their growth and innovation performance can be divided between those that deal with the inherent quality of the company and those outside the company.

In the literature, there is no clear trend to explain the corporate improvement. In particular, the heterogeneities between micro companies throughout and with countries -concerning policy climates, challenge interconnectivity, environment support, skills and strategies-imply that different factors will play a role at different times in the process. Thus although some factors are more important in a given context than others, a "recipe" for business success is not available, or there is a trend to explain the development of a company through a heterogeneous group of companies.

Company upgrading calls for a right combination of inner and outer factors in an 'onion' model, in different waves of academic discourse on corporate development the 'internal' and 'external' perspectives were increasingly dominant.

In summary, this paper reveals that upgrading is a complex phenomenon which requires various conditions in the external environment and about the quality of the contractor and the company to be met to upgrade. These factor combinations are not standardized due to the country and case susceptibility. However, this literature review provides some insight into the role of different factors in the four principal layers of "onion." Due to the lack of consistent conceptual definitions, operations, and measurements of corporate development and upgrade, more synthesized and generalizable conclusions about company upgrading are rejected.

Also, the availability of useful data for the panel (in all countries) impacts works quality and insights. Therefore, panel data is needed for more interdisciplinary research into micro, small and medium-sized enterprises (MSMEs).

\section{References}

[1] C. Liedholm and D. Mead, "The Dynamics of Micro and Small Enterprises in Developing Countries," World Dev., vol. 26, no. 1, 1998.

[2] A. Azis and A. H. Rusland, Peranan Bank Indonesia di Dalam Mendukung Pengembangan Usaha Mikro, Kecil, dan Menengah, no. 21. Jakarta: Pusat Pendidikan dan Studi Kebanksentralan (PPSK) Bank Indonesia, 2009.

[3] L. E. Greiner, "Evolution and revolution as organizations grow. 1972.," Harvard business review, vol. 76, no. 3. pp. 322-329, 1998.

[4] I. Adizes, Organizational Passages-Diagnosing and Treating Lifecycle Problems of Organizations, vol. 8. 1979.

[5] C. Churchill, N. and L. Lewis, V., "The Five Stages of Small Business Growth," Harvard Business Review, vol. 61, no. May. pp. 30-50, 1983.

[6] M. Scott and R. Bruce, "Five stages of growth in small business," Long Range Plann., vol. 20, no. 3, pp. 45-52, 1987.

[7] J. Humphrey and H. Schmitz, "Governance and Upgrading: Linking Indutrial Cluster and Global Value Chain Research,” 120, 2000. 
[8] C. Reeg, Micro, Small and Medium Enterprise Upgrading in India. Bonn: The German Development Institute, 2013.

[9] C. Reeg, “, Small and Medium Enterprise Upgrading in Low- and MiddleIncome Countries," A Literature Review. Deutsches Institut für Entwicklungspolitik gGmbH, Bonn, pp. 13-88, 2013.

[10] M. Loewe et al., "Which Factors Determine the Upgrading of Small and Medium-Sized Enterprises.” Deutsches Institut für Entwicklungspolitik gGmbH, Bonn, 2013.

[11] A. H. Milagrosa, "Micro and Small Enterprise Upgrading in the Philippines." Deutsches Institut für Entwicklungspolitik gGmbH, Bonn, 2014.

[12] A. S. Goldberger, "Structural Equation Methods in the Social Sciences," Econometrica, vol. 40, no. 6, pp. 979-1001, 1972.

[13] J. W. Keesling, "Maximum Likelihood Approaches to Causal Analysis," University of Chicago, 1972. 